\title{
Intra- and extracellular calcium and hypertension
}

\author{
BY ANTHONY M. HEAGERTY \\ Department of Medicine, Clinical Sciences Building, Leicester Royal Infirmary, \\ Leicester LE2 7LX
}

Individuals who have blood pressures at the upper end of the distribution curve are at increased risk of circulatory diseases such as myocardial infarction and cerebrovascular accident. Their hypertension appears to represent the result of an interaction between the appropriate genetic background and the environment to which they are exposed. Because of these factors, high blood pressure has achieved prominence in the public eye, not least because patients are unaware that they have it and because effective detection and treatment can substantially reverse the risk of stroke. This is coupled with an increasingly closer scrutiny of our dietary intake because of the contention that nutritional factors contribute to many disease states that afflict acculturated societies. Moreover, the modification of dietetic habits has become a cornerstone in the fight to reduce mortality from ischaemic heart disease, and possible nutritional manipulations that might ameliorate high blood pressure are clearly attractive. There is undeniable evidence now that prudent weight reduction is beneficial in the fight against hypertension; similarly a modest increase in exercise, as well as reductions in moderate or excessive alcohol intake are recommended. The debate continues to rage over whether or not an excessive dietary salt intake contributes to the genesis of essential hypertension. On the one hand it does appear that moderate restriction of sodium intake is beneficial in the established phase of the disease; indeed it may obviate the need for drug therapy. On the other hand, there is no evidence that restricting the salt intake of the normotensive individual prevents the subsequent development of hypertension. Against this background, researchers have begun to examine the possible roles of other dietetic components, and it is in this context that much interest was aroused at the beginning of the 1980 s by the suggestion that calcium deficiency might be contributing to hypertension, and dietary Ca supplementation would be a useful treatment. It is the purpose of the present paper to summarize some of the current findings related to intracellular $\mathrm{Ca}$ and their possible implications in the generation of hypertension, and the recent dietary intervention studies designed to show whether changes in $\mathrm{Ca}$ intake can lower established hypertension.

\section{MEMBRANE FUNCTION AND HYPERTENSION}

A variety of abnormalities of cellular electrolyte fluxes have been described in association with essential hypertension (Heagerty et al. 1986). The relationship between these abnormalities and blood pressure is still the subject of conflicting hypotheses and debate. In some cases, confounding factors may explain the association. For example, the epidemiological association between increased lithium- $\mathrm{Na}$ counter-transport and blood pressure is partly at least attributable to differences in plasma lipids between individuals (Hunt et al. 1986). The many disturbances of membrane function now described are diverse, and range from passive movements of univalent ions to active 
transport of monovalent and divalent ions such as $\mathrm{Ca}$. The studies of $\mathrm{Ca}$ handling indicate that there are changes in the binding of the ion to the inner lamella of the plasma membrane, as well as influx and extrusion across this boundary. More recently, detailed studies in genetically hypertension-prone rats have examined the concentration of intracellular free $\mathrm{Ca}$ : several reports indicate that this is raised in both blood cells as well as in myocytes (Bruschi et al. 1985, 1988; Furspan \& Bohr, 1986). In man, no study of this kind has been carried out on vascular smooth muscle cells, but in platelets from hypertensive patients, Erne et al. (1984) reported that the intracellular free Ca was increased. This has been confirmed in platelets by other workers (Bruschi et al. 1985; Cooper et al. 1987) but not in other tissues (Shore et al. 1985; Bing et al. 1986a,b).

The control of cytosolic free $\mathrm{Ca}$ concentrations is clearly of crucial importance in terms of the physiological activity of cells such as vascular myocytes. In view of the studies in hypertension that suggest that membrane phase transition temperature and viscosity are abnormal, we have postulated that there is a genetically determined abnormality of the physico-chemical make-up composition of the plasma membrane in this disease (Bing et al. $1986 a, b)$. Such a perturbation probably lies in the lipid component of the membrane, and as such might explain all the phenomena described at a cellular level in hypertension. In this respect, some workers have examined the fatty acid composition of cell membranes and a reduction of linoleic acid content has been observed in spontaneously hypertensive rats (SHR) and man (Heagerty \& Ollerenshaw, 1987). Like some of the reported ion transport abnormalities this may be only a manifestation of the blood pressure process rather than representative of the pathogenetic defect, or merely even just reflect a dietary difference of the population under test. However, the more complex phospholipids into which these fatty acids are incorporated are metabolically active and control the transmembrane passage of electrolytes as well as membrane structure and orientation. In this regard there has been considerable interest in the phosphoinositide lipids located in the cell membrane, not least because this relatively minor fraction of phospholipids is important in the control of $\mathrm{Ca}$ binding to the inner lamella, as well as the release of $\mathrm{Ca}$ from sarcoplasmic reticulum and extrusion of $\mathrm{Ca}$ out of the cell (Heagerty \& Ollerenshaw, 1987). These functions are executed by the hydrolysis of the phosphoinositide lipid, phosphatidylinositol-1,4,5-bisphosphate, to liberate inositol-1,4,5trisphosphate (Ins 1,4,5- $\mathrm{P}_{3}$ ) and the lipid 1,2-diacylglycerol (1,2-DAG). Ins 1,4,5- $\mathrm{P}_{3}$ is a potent intracellular ligand stimulating the release of stored intracellular $\mathrm{Ca}$; in addition recent evidence suggests that it may have a role in regulating $\mathrm{Ca}$ entry from outside the cell (Synder et al. 1988). Because of the recognized importance of enhanced vascular resistance in the genesis of hypertension, studies of the phosphoinositide-signalling system and its metabolites have been performed in a variety of models of hypertension. In SHR at 5 weeks of age, before blood pressure and vascular structural changes had occurred, aortic inositol phosphate accumulation was greater in both the basal and noradrenaline-stimulated state, suggesting that the system is overactive in the early stages of the disease. However, later, at 19 weeks, this is no longer observed in the SHR (Heagerty \& Ollerenshaw, 1986). In man there are few studies, although our findings suggest that a similar picture is seen in hypertension (Riozzi et al. 1987).

Recent research would indicate that hypertension is a disease characterized by architectural changes in the walls of 'resistance' arteries. Therefore, an overactive inositol phosphate signalling system may be of extreme importance in the genesis of the structural changes occurring as the blood pressure rises. Naturally it must be conceded 
that the imposition of a pressure load on the vascular wall may be the stimulus to raise inositol phosphate production. Indeed, the process of vascular distension is sufficient to open stretch-dependent $\mathrm{Ca}$ channels, and distension of the atrium will stimulate inositol phosphate release (Heagerty et al. 1988; Von Harsdorf et al. 1988). Thus, mobilization of inositol lipid hydrolysis might be secondary to the pressure-inducing stimulus. However, several groups have now demonstrated that the myocytes of SHR grow faster in culture than those from normotensive rat strains, and in culture inositol phosphate production is enhanced (Resink et al. 1987). Moreover, Smeda et al. (1988) have recently reported that the SHR demonstrates alterations in the structure of the renal vasculature which are independent of hypertension and not affected by antihypertensive medication. Hence, results are emerging which suggest that load-independent growth occurs in vascular myocytes of genetically hypertension-prone rats, both in culture and in intact vascular. beds. The increased production of Ins $1,4,5-\mathrm{P}_{3}$ would be compatible with this phenomenon also, as would the finding that the histological change observed in resistance arteries of SHR is hyperplasia, whereas in experimentally induced models of hypertension there is vascular hypertrophy.

The mechanisms by which growth is promoted in these tissues remains uncertain. The growth factors themselves are unknown; load itself may induce inositol hydrolysis by stretching the vascular wall as indicated previously, but in addition to this stimulus it is recognized that noradrenaline, vasopressin and angiotensin II all act by increased hydrolysis of phosphatidylinositide-1,4,5 bisphosphate. Moreover, these pressor hormones can induce cellular proliferation in culture, independent of pressure-mediated effects. The intracellular responses that are provoked remain uncertain. Until recently it had been believed that increased inositol lipid breakdown was associated with a prolonged rise in 1,2-DAG production, which would activate protein kinase $\mathrm{C}$ and increase cytosolic $\mathrm{pH}$ by activating $\mathrm{Na}$ ion/hydrogen ion exchange. This electroneutral antiport is one of the cellular mechanisms at work in controlling internal pH; moreover, a rise in intracellular $\mathrm{pH}$ had been demonstrated to occur during the growth cycle, and blockade of $\mathrm{Na}^{+} / \mathrm{H}^{+}$exchange prevented both the change in $\mathrm{pH}$ and the expected cellular proliferation induced by mitogens. In agreement with this, Griendling et al. (1986) reported that angiotensin II produced a biphasic but sustained rise in 1,2-DAG in cultured bovine aortic myocytes, and Berk et al. (1987) have demonstrated brief acidification followed by prolonged alkalinization of the cytoplasm in the same tissue using angiotensin II. However, there are problems with the interpretation of these findings; the experiments were conducted in Hepes-containing buffers, which are free of bicarbonate. More recently, Ganz et al. (1989) have shown that bicarbonate-dependent intracellular $\mathrm{pH}$ regulatory mechanisms are important for cellular $\mathrm{pH}$ homeostasis; these processes are automatically abolished when bicarbonate is excluded from tissue buffers. Thus, when experiments were carried out in intact arteries in bicarbonate-containing solutions, stimulation with noradrenaline produced a decrease in intracellular pH (Izzard \& Heagerty, 1989), in accord with Ganz et al. (1989). Nevertheless, the resting internal $\mathrm{pH}$ was higher in SHR compared with normotensive (WKY) rats (Izzard \& Heagarty, 1989). Therefore, in agreement with our previous findings on phosphoinositide lipid metabolism in hypertension, $\mathrm{pH}$ is higher in SHR. Our experiments do not indicate whether $\mathrm{Na}^{+} / \mathrm{H}^{+}$activity is enhanced, although this has been suggested by Feig et al. (1987).

In summary, in genetically determined hypertension there appears to be evidence that 
the cell membrane is structurally deranged and functionally abnormal. Some of the phospholipids in the plasma membrane can be implicated in the pathway required for cell growth; these phosphoinositide lipids are hydrolysed faster in young, genetically hypertension-prone rats, when vascular growth will be occurring and blood pressure is rising. Recent findings suggest that intracellular $\mathrm{pH}$ is increased in the arteries of such animals when the vessels are undergoing vascular remodelling. We eagerly await further experiments designed to induce hypertension and to investigate the vascular growth process in more detail.

\section{EPIDEMIOLOGICAL ASSOCIATIONS OF CALCIUM INTAKE WITH HYPERTENSION}

From what has been outlined previously, it would seem strange that a manipulation designed to raise extracellular $\mathrm{Ca}$ should lower hypertension. The rationale for such a nutritional manoeuvre arose from epidemiological findings suggesting that our Western diet is deficient in Ca. McCarron et al. (1982) evaluated Ca intake in newly diagnosed hypertension patients using a computer-assisted dietary recall protocol. Compared with an age-, race- and sex-matched normotensive control group, the hypertensive patients reported significantly less $\mathrm{Ca}$ intake. Two points should be noted: first, socio-economic background was not controlled, and second, it is well-established that dietary recall studies are fraught with difficulty (Block, 1982). McCarron et al. (1984) then examined a larger data-base from the National Health and Nutrition Survey (NHANES). This study was conducted by the National Centre for Health Statistics to collect information on health and nutritional status for a scientifically designed representative sample of the US population. From the original 20749 people surveyed between 1971 and 1974 in sixty-five locations, McCarron et al. (1984) took 10372 adults who were not receiving a special diet or treatment for hypertension: these were aged 18-74 years. In those patients considered to be hypertensive, significantly lower consumptions of $\mathrm{Ca}$, potassium, vitamin $A$ and vitamin $C$ were observed. However, this work has been the subject of intense criticism and controversy as regards subject selection (Kaplan \& Meese, 1986), cohort standardization, the definition of hypertension adopted, and the known bias of the NHANES survey towards lower socio-economic groups. Feinleib et al. (1984) re-analysed the data weighting for age and failed to replicate the findings of McCarron et al. (1984). Harlan et al. (1984) undertook a more detailed analysis of the same data-base and examined 3854 subjects to look for an association between nutritional intake and both systolic and diastolic blood pressure. In this study, higher blood pressure was associated with a lower intake of $\mathrm{Ca}$, although the association was described as 'fragile'. However, in the same study, dietary $\mathrm{Ca}$ intake was inversely correlated to diastolic pressure in women and positively correlated with systolic pressure in men. The use of dietary recall seems the central issue with regard to the validity of these findings. As Kolata (1984) points out, when researching a chronic disease such as hypertension, an assessment of food intake over $24 \mathrm{~h}$ seems rather insignificant.

Garcia-Palmieri et al. (1984) have published information on 7932 Puerto Rican males aged 45-64 years. The Puerto Rican population have an estimated mean intake of Ca which is within the range recommended by the (US) National Research Council (1980). They found that among urban and rural men without baseline coronary heart disease, and not on antihypertensive medication, there was a 'modest' inverse relationship 
between milk consumption and definite hypertension. The authors stated that it could not be concluded with certainty that this was a true relationship. Again information was obtained on diet over a $24 \mathrm{~h}$ period. Of the diet recalls, $40 \%$ included food from recipe sources, which were not included in the calculation for the $\mathrm{Ca}$ content of the diet, the authors contending that the amount of extra food from sources was small.

Similarly Reed et al. (1985), in a study of 8000 Japanese men in Hawaii, reported that $\mathrm{Ca}$ from dairy foods was inversely associated with blood pressure whilst $\mathrm{Ca}$ from non-dairy foods was not. $K$, protein, milk and alcohol were also inversely associated with blood pressure. The authors concluded that, in this type of study, the independent role of any specific nutrient cannot be conclusively separated from the possible effects of other nutrients.

Similar criticisms can be levelled at other studies which have analysed possible nutrient associations with blood pressure. Harlan et al. (1985) used a further large population data-base (NHANES-II), principally to look for an association between lead and blood pressure. In the course of the study, dietary recall studies were carried out. Dietary $\mathrm{Ca}$ intake was lower in younger hypertensive men, and in women, and in older hypertensive females. Ca intake was weakly inversely related to blood pressure in women but not men. Thus, the evidence for a role of dietary $\mathrm{Ca}$ in the aetiology of hypertension must be regarded as weak and inconclusive.

\section{DIETARY MANIPULATIONS OF CALCIUM IN HYPERTENSION}

The intake of $\mathrm{Ca}$ is mainly derived from dairy products (Beilin, 1987) and is strongly associated with dietary $\mathrm{K}$, protein and energy intake as well as physical exercise and socio-economic background. In addition there is an inverse correlation with age and alcohol use (Beilin, 1987). Trials involving the use of Ca supplements were encouraging initially. However, these have been criticized on the grounds of poor design and analysis. More recently one study of young, mild hypertensives was negative, although the authors did suggest that patients who complied well showed some falls in diastolic blood pressure (Grobbee \& Hofman, 1986). However, four well-controlled studies have been negative (Strazzullo et al. 1986; Zoccali et al. 1986; Cappuccio et al. 1987; Siani et al. 1988).

In conclusion there seems no reason at the present time to advocate an increase in dietary $\mathrm{Ca}$ intake as a dietetic measure aimed at lowering established hypertension.

I am extremely grateful to the British Heart Foundation for supporting my research.

\section{REFERENCES}

Beilin, L. J. (1987). Diet and hypertension: critical concepts and controversies. Journal of Hypertension S, Suppl. 5, 447-457.

Berk, B. C., Aronow, M. S., Brock, T. A., Cragoe, E., Gimbrone, M. A. \& Alexander, R. W. (1987). Angiotensin II-stimulated $\mathrm{Na}^{+} / \mathrm{H}^{+}$exchange in cultured vascular smooth muscle cells. Journal of Biological Chemistry 262, 5057-5064.

Bing, R. F., Heagerty, A. M., Jackson, J. A., Thurston, H. \& Swales, J. D. (1986a). Leucocyte ionized calcium and sodium content and blood pressure in humans. Hypertension 8, 483-488.

Bing, R. F., Heagerty, A. M., Thurston, H. \& Swales, J. D. (1986b). Ion transport in hypertension: are changes in the cell membrane responsible? Clinical Science 71, 225-230.

Block, G. (1982). A review of validations of dietary assessment methods. American Journal of Epidemiology $115,492-504$. 
Bruschi, G., Bruschi, M. E., Caroppo, M., Orlandini, G., Spaggiari, G. \& Cavatorta, A. (1985). Cytoplasmic free $\left(\mathrm{Ca}^{2+}\right)$ is increased in the platelets of spontaneously hypertensive rats and essential hypertensive patients. Clinical Science 68, 179-184.

Bruschi, G., Bruschi, M. E., Regolisti, G. \& Borghetti, A. (1988). Myoplasmic $\mathrm{Ca}^{2+} /$ force relationships studied with fura-2 during stimulation of rat aortic smooth muscle. American Journal of Physiology 254, $840-854$.

Cappuccio, F. P., Markandu, N. D., Singer, D. R. J., Smith, S. J., Shore, A. C. \& MacGregor, G. A. (1987). Does oral calcium lower high blood pressure? A double blind study. Journal of Hypertension 5, 67-72.

Cooper, R. S., Shamsi, W. \& Katz, S. (1987). Intracellular calcium and sodium in hypertensive patients. Hypertension 9, 224-229.

Erne, P., Bolli, P., Burgisser, E. \& Buhler, F. R. (1984). Correlation of platelet calcium with blond pressure: effect of antihypertensive therapy. New England Journal of Medicine 310, 1084-1088.

Feig, P. U., D'Ochio, M. A. \& Boylan, J. W. (1987). Lymphocyte membrane sodium-proton exchange in spontaneously hyperactive rats. Hypertension 9, 282-288.

Feinleib, N., Lenfaut, C. \& Miller, S. A. (1984). Hypertension and calcium. Science 226, 384-386.

Furspan, P. B. \& Bohr, D. F. (1986). Calcium-related abnormalities in lymphocytes of genetically hypertensive rats. Hypertension 8, Suppl. 2, 123-126.

Ganz, M. B., Boyarsky, G., Sterzel, R. B. \& Boron, W. F. (1989). Arginine vasopressin enhances $\mathrm{pH}_{\mathrm{i}}$ regulation in the presence of $\mathrm{HCO}_{3}{ }^{\circ}$ by stimulating the acid-base transport systems. Nature 337, 648-651.

Garcia-Palmieri, M. R., Costas, R., Cruz-Vidal, M., Sorlie, P. D., Tillotson, J. \& Havlik, R. J. (1984). Milk consumption, calcium intake, and decreased hypertension in Puerto Rico. Hypertension 6, 322-328.

Griendling, K. K., Rittenhouse, S. E., Brock, T. A., Ekstein, L. S., Gimbrone, M. A. \& Wayne Alexander, R. (1986). Sustained diacylglycerol formation from inositol phospholipids in angiotensin II-stimulated vascular smooth muscle cells. Journal of Biological Chemistry 261, 5901-5906.

Grobbee, D. E. \& Hofman, A. (1986). Effect of calcium supplementation on diastolic blood pressure in young people with mild hypertension. Lancet ii, 703-706.

Harlan, W. R., Hull, A. L., Schmouder, R. L., Landis, J. R., Thompson, F. E. \& Larkin, F. A. (1984). Blood pressure and nutrition in adults: The National Health and Nutritional Examination Survey. American Journal of Epidemiology 120, 17-27.

Harlan, W. R., Landis, J. R., Schmouder, R. L., Goldstein, N. G. \& Harlan, J. C. (1985). Blood lead and blood pressure: relationship in adolescent and adult US population. Journal of the American Medical Association 253, 530-534.

Heagerty, A. M., Izzard, A. S., Ollerenshaw, J. D. \& Bund, S. J. (1988). Blood vessels and human essential hypertension. International Journal of Cardiology 20, 15-28.

Heagerty, A. M. \& Ollerenshaw, J. D. (1986). Abnormal vascular phosphoinositide hydrolysis in the spontaneously hypertensive rat. British Journal of Pharmacology 89, 803-807.

Heagerty, A. M. \& Ollerenshaw, J. D. (1987). The phosphoinositide signailing system and hypertension. Journal of Hypertension 5, 515-524.

Heagerty, A. M., Riozzi, A., Brand, S. C., Bing, R. F., Thurston, H. \& Swales, J. D. (1986). Membrane transport of ions in hypertension: a review. Scandinavian Journal of Clinical and Laboratory Investigation 46, 54-63.

Hunt, S. C., Williams, R. R., Smith, J. B., \& Ash, K. O. (1986). Associations of three erythrocyte cation transport systems with plasma lipids in Utah subjects. Hypertension 8, 30-36.

Izzard, A. S. \& Heagerty, A. M. (1989). The measurement of internal pH in resistance arterioles: evidence that intracellular pH is more alkaline in SHR than WKY animals. Journal of Hypertension 7, 173-180.

Kaplan, N. M. \& Meese, R. B. (1986). The calcium deficiency hypothesis of hypertension: a critique. Annals of Internal Medicine 105, 947-955.

Kolata, G. (1984). Does a lack of calcium cause hypertension? Science 225, 705-706.

McCarron, D. A., Morris, C. D. \& Cole, C. (1982). Dietary calcium in human hypertension. Science 217, 267-269.

McCarron, D. A., Morris, C. D., Henry, H. J. \& Stanton, J. K. (1984). Blood pressure and nutrient intake in the United States. Science 224, 1392-1398.

National Research Council (1980). Recommended Dietary Allowances 9th revised ed. Washington DC: National Academy of Sciences.

Reed, D., McGee, D., Yano, K. \& Hankin, J. (1985). Diet, blood pressure and multicollinearity. Hypertension 7, 405-410. 
Resink, T. J., Scott-Burden, T., Baur, U. \& Buhler, F. R. (1987). Increased proliferation rate and phosphoinositide turnover in cultured smooth muscle cells from spontaneously hypertensive rats. Journal of Hypertension 5, Suppl. 5, 145-148.

Riozzi, A., Heagerty, A. M., Ollerenshaw, J. D. \& Swales, J. D. (1987). Erythrocyte phosphoinositide metabolism in essential hypertensive patients and their normotensive offspring. Clinical Science 73, 29-32.

Shore, A. C., Beynon, G. W., Jones, J. C., Markandu, N. D., Sagnella, G. A. \& MacGregor, G. A. (1985). Mononuclear intracellular free calcium: does it correlate with blood pressure? Journal of Hypertension 3, $183-187$.

Siani, A., Strazzullo, P., Guglielmi, S., Pacioni, D., Giacco, A., Iacone, R. \& Mancini, M. (1988). Controlled trial of low calcium versus high calcium intake in mild hypertension. Journal of Hypertension 6, 253-256.

Smeda, J. S., Lee, R. M. K. W. \& Forrest, J. B. (1988). Prenatal and postnatal hydralazine treatment does not prevent renal vessel wall thickening in SHR despite the absence of hypertension. Circulation Research 63, 534-542.

Strazzullo, P., Siani, A., Guglielmi, S., Di Carlo, A., Galletti, F., Cirillo, M. \& Mancini, M. (1986). Controlled trial of long term oral calcium supplementation in essential hypertension. Hypertension 8 , $1084-1088$.

Synder, P. M., Krause, K. \& Welsh, M. J. (1988). Inositol trisphosphate isomers, but not inositol 1,3,4,5-tetrakisphosphate, induce calcium influx in xenopus laevis oocytes. Journal of Biological Chemistry 263, 11048-11051.

Von Harsdorf, R., Lang, R., Fullerton, M., Smith, A. I. \& Woodcock, E. A. (1988). Right atrial dilation increases inositol-(1,4,5)-trisphosphate accumulation: implication for the control of atrial natriuretic peptide release. FEBS Letters 233, 201-205.

Zoccali, C., Mallami, F., Delfino, D., Ciccarelli, M., Parlongo, S., Lellamo, D., Moscato, D. \& Maggiore, A. (1986). Long term oral calcium supplementation in hypertension: a double blind randomised crossover study. Journal of Hypertension 4, Suppl. 6, 676-678. 